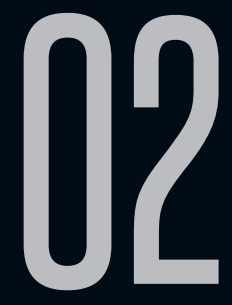

\title{
ENTREVISTA COM DAVID ROAS
}

Flavio García

Recebido em 01 abr 2016. Flavio García é Pós-Doutor pela UC (2016), UFRGS Aprovado em 29 abr 2016. (2012) e UFRJ (2008), Doutor pela PUC-Rio (1999) e Mestre pela UFF (1995). Professor Associado da UERJ, atua nos Mestrado e Doutorado na área de Estudos de Literatura. Foi o primeiro coordenador do GT ANPOLL "Vertentes do Insólito Ficcional" (julho de 2011 a junho de 2016) e é líder do GP Diretório de Grupos do CNPq "Nós do Insólito: vertentes da ficção, da teoria e da crítica" (desde 2001). Vem publicando variados títulos (livros de autoria própria ou organizados, capítulos de livro e artigos em periódicos) sobre as "vertentes do insólito ficcional" no Brasil e no exterior. CV Lattes: http://lattes.cnpq.br/4242057381476599. 


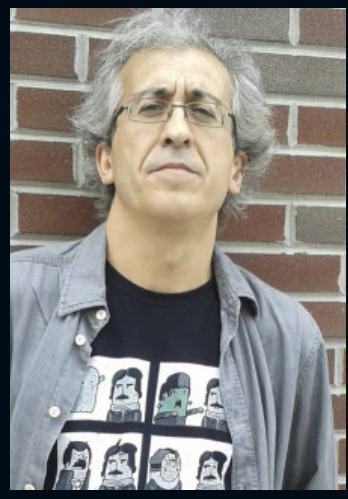

David Roas (Deus) nasceu em Barcelona, Espanha, em julho de 1965, onde atua como professor titular de teoria da literatura e literatura comparada na Universitàt Autónoma (UAB). Além de professor universitário e, consequentemente, pesquisador, Roas é ficcionista e crítico premiado, dedicando-se à literatura fantástica.

Na UAB, Roas coordena o Grupo de Estudios sobre lo Fantástico - GEF (http://www.lofantastico.com/) e responde pela editoria da revista Brumal (http:// revistes.uab.cat/brumal/index), projetos dos quais também participam pesquisadores brasileiros. No acordo de cooperação interinstitucional firmado entre a UERJ e a UAB, entorno da fantástico e tendo por organismos executores o Seminário Permanente de Estudos Literários da UERJ (SePEL.UERJ) e o GEF, Roas é o representante de sua Universidade.

Em 2001, com a publicação de Teorías de lo fantástico, Roas ganha visibilidade no cenário internacional, demonstrando amplo, vasto e diversificado conhecimento do tema, além de invejável articulação com demais pesquisadores, teóricos e críticos, como Tzvetan Todorov, Teodosio Fernández, Irène Besière, Jean Bellemin-Noël, Roger Bozetto, Rosalba Campra, Rosemary Jackson, Martha Nandorfy, Susana Reisz e Jaime Alarazki.

Em meio a diversas e diferentes incursões pelo mundo do fantástico, como teórico ou crítico, Roas publicou estudos sobre a obra de Allan Poe, sobre o medo e o terror, sobre vertentes literárias do fantástico na Espanha etc., tendo sido galardoado, em 2011, com o Premio Málaga de Ensayo, atribuído a Tras los límites de lo real: Una definición de lo fantástico, e, como ficcionista, nesse mesmo ano, ganhou o VIII Premio Setenil de melhor livro de contos pela publicação de Distorsiones (2010). 
Dentre os estudiosos contemporâneos do fantástico pelo mundo afora, Roas se destaca, com especial expressividade, mantendo relações com núcleos de produção tanto ficcional, quanto teórica e crítica, em vários países das Américas e da Europa, além de contar com uma juventude demasiado promissora de ainda muito mais por vir.

P.: Bom dia, David. Estamos aqui hoje em Barcelona, 6 de fevereiro de 2016. Mais um encontro bastante sólito das nossas passagens insólitas pelo fantástico, por essa parceria. Vamos ouvir um pouquinho... algumas coisas que você pensa... sobre os nossos projetos conjuntos, sobre o que andamos fazendo, nossos acontecimentos. Hoje, inegavelmente, quando se pensa em fantástico, na teoria, na crítica, no pensamento fantástico e, de certa maneira, já na ficção, David Roas é uma das referências contemporâneas mais vivas. David, para você, o que é o fantástico?

R.: Haré una definición rápida y sencilla: para mí, lo fantástico es una manera de subvertir la realidad. Yo creo que lo fantástico siempre tiene que ver con algo que destruye nuestra idea de lo real. Sea un monstruo, sea un pequeño acontecimiento banal, pero que es imposible. Yo creo que, para no extenderlos en una definición muy larga, para mí lo fantástico siempre es el choque entre lo posible y lo imposible, entre lo real y lo que no puede estar aquí. Y eso siempre va a provocar una transgresión y el miedo de la persona que contempla o que se enfrenta lo imposible.

P.: Ao longo do tempo, o fantástico como você pensa, como você vê, como você constrói, na condição de narrador, é, sempre foi a mesma coisa ou modificou-se, transmutou-se, alterou-se? 
R.: Yo creo que lo fantástico se mantiene y a la vez muta, cambia. Para mí, desde que lo fantástico existe, sea con la novela gótica del siglo XVIII, sea con el romanticismo, que yo creo que es cuando empieza lo fantástico de verdad, para mí hay una constante a lo largo de la historia que llega hasta hoy que es esa idea que antes planteaba: el choque, el conflicto lo posible y lo imposible. Con el tiempo, lo que ha cambiado son las maneras de trasladar esto al papel, a la pantalla, a la televisión, al cómic, porque ha cambiado nuestra forma de relacionarnos con la realidad. Ahora es muy difícil hacer una historia con fantasmas o con vampiros, con monstruos tradicionales que nos inquiete tanto como lo que han podido escribir Cortázar, Borges o Cristina Fernández Cubas (por citar tres maestros en español), o autores más recientes que hacen que el (aparente) equilibrio de la realidad cotidiana se rompa. Por tanto, lo que está detrás siempre es lo mismo: el choque entre lo posible y lo imposible, la inquietud del receptor o de la persona que se enfrenta a lo fantástico; lo que ha cambiado es la superficie. Por eso me parece que narrar historias con casas encantadas es muy aburrido, porque son historias muy conocidas, poco o nada sorprendentes... Ahora bien, si la cámara que me está filmando empezara a levitar, eso sí que me provocaría una terrible inquietud... fantástica.

P.: Durante muito tempo, a literatura fantástica esteve à margem, vista como marginal, fora dos cânones literários. As historiografias literárias, inclusive, não dão ao fantástico, ainda hoje, certa importância. Todavia, na atualidade, o fantástico ganha muito espaço. Na sua última fala, você destacou a banda 
desenhada, o cine... Eu perguntaria: qual a importância do cinema para o fantástico na atualidade?

R.: El cine (y la televisión, hermanos de sangre) es muy importante porque continúa explorando formas de inquietar al espectador a través de lo fantástico. Porque hay cosas que la literatura no puede hacer, y el cine lo consigue (también a la inversa). Eso sí, siempre que el cine apueste por buscar nuevas formas... Como dije, seguir leyendo sobre fantasmas o caserones góticos es realmente aburrido, porque no sorprende, y si no sorprende poco o nada va a inquietar. El cine de Hollywood se ha vuelto un cine muy fácil, muy tonto, porque sigue jugando (y repitiéndose) con fantasmas, casas encantadas, niños raros... Todo lo contrario que el cine japonés, o lo que está ocurriendo en series de TV actuales, donde se están narrando impactantes historias en las que lo fantástico sigue siendo perturbador, no un simple espectáculo banal. Por eso creo que el cine seguirá siendo una de las formas fundamentales de experimentación, pero siempre que escape tipo de cine que es hecho toda la vida, que empieza a ser muy cansado. Frente a Hollywood hay un cine independiente... Pienso en películas como la australiana The Babadook, que narra una historia aparentemente típica, pero que rápidamente escapa de lo obvio y trillado, y conduce al espectador a enfrentarse con la auténtica inquietud. No exagero si digo que la he visto 6 o 7 veces y sigue dándome miedo. Incluso ahora, recordándola, se me pone la carne de gallina.

P.: Você diria, então, que a linguagem que incorporou a imagem, o som, o movimento para onde o fantástico teria migrado naturalmente 
com uma média, contribui para tirar o fantástico da marginalidade e trazer o fantástico para um espaço mais canônico?

R.: Difícil responder. No creo que lo fantástico llegue a ser canónico, lo fantástico siempre va a ser más o menos periférico, marginal, porque todavía las formas "respetables", con muchas comillas, son las formas realistas. Los espectadores, los lectores están más habituados y necesitan más de lo real, porque lo fantástico inquieta, porque lo fantástico te hace pensar en que, quizá, la realidad funcione así, que tú eres un ser extraño, que hay un monstruo dentro de ti... Y eso sin negar la enorme cantidad de obras fantásticas muy populares en cine $y$, sobre todo, en la TV actual (fundamentalmente estadounidense): desde Lost a American Horror Story, The Walking Dead, Penny Dreadful, o la francesa Les Revenants, que da un tratamientomuy nuevo al tema del zombi. Es decir, que cada vez hay más público, pero siempre será menor si lo comparamos con el público de otro tipo de literatura o de cine o de televisión más realista. En definitiva, vivimos muy buenos tiempos para lo fantástico, pero éste siempre ocupará, y me parece bien, un lugar no central en el arte.

P.: David é um ficcionista, é um crítico, um teórico, é um professor, é um pesquisador e, tanto como ficcionista como teórico e crítico, é premiado. Como você, cidadão, ser humano, indivíduo pensa essa dualidade de ser premiado tanto como ficcionista tanto como teórico e crítico?

R.: A mí me da mucha ilusión que me den premios en donde sea, ¿no? Creo que he logrado combinar en mi persona lo 
que Stevenson inventó para Jekyll y Hyde. Me explicaré. En mí conviven dos seres: el Jekyll teórico de lo fantástico, y el Hyde escritor, que también suele usar mucho lo fantástico en sus relatos. Por ahora, he logrados que los dos no se peleen mucho. Son buenos amigos y trabajan bien, porque cada uno se olvida del otro cuando trabaja... Cuando escribo ficción fantástica no estoy pensando - al menos conscientemente en si estoy utilizando un narrador tal, o quiero hacer tal cosa... sé que lo estoy haciendo, sólo faltaría, pero trato de separar el mundo de la reflexión teórica y el mundo de la creación ficcional. Un ejemplo: lo estricto que soy investigando sobre lo fantástico, deja de funcionar cuando escribo, pues no me preocupa mezclar fantástico con ciencia ficción, con humor, con lo que sea... Cuando soy Hyde, "mato" a Jekyll, y a la inversa. Aunque es evidente que vivir en esos dos mundos me ha ayudado mucho: gracias a cultivas la ficción fantástica creo que he afinado más mis trabajos teóricos sobre lo fantástico.

P.: De sua obra ficcional, que já não é tão pequena, e é diversificada no gênero e em subgêneros narrativos (microcontos, microrrelatos, contos, novelas), em títulos premiados, outros títulos selecionados em processo de premiação. Qual obra, qual narrativa sua você destacaria e por que você destacaria essa narrativa?

R.: Por supuesto, un padre siempre quiere por igual a todos sus hijos... Yo sólo tengo un hijo real, pero ya varios de ficción. Si tuviera que destacar uno sólo de mis hijos ficcionales - de mis libros - me quedaría con Distorsiones, porque ese libro es el que mejor representa mi idea de lo fantástico (también presente 
en los otros libros de cuentos; en mis dos novelas, sin embargo, he apostado más por los juegos con el realismo mezclado con lo grotesco y el humor). De algún modo, muchos de los cuentos de Distorsiones logran transmitir lo que yo también pienso cuando teorizo y reflexiono sobre lo fantástico: "Das Kapital", que narra un inverósimil viaje en avión donde los pasajeros de primera clase no tienen turbulencia pero los de segunda sí (la lectura política es evidente); o "Excepciones.", sobre un tipo que no puede entrar en su casa (la puerta le expulsa de nuevo a la calle); o varios de los microrrelatos donde exploro los límites de lo real. Si pienso exclusivamente en lo fantástico, es el libro del que estoy más contento. El año pasado publiqué mi último libro (Bienvenidos a Incaland), del que también estoy muy satisfecho, en el que para narrar un viaje real que hice por Perú tuve que combinar lo realista y lo fantástico, porque si no, no podía contar todo lo que vi, sentí y pensé ante esa nueva realidad. Pero, insisto, creo que Distorsiones sería lo que mejor sintetiza mi idea de lo fantástico.

P.: Trás los límites de lo real, livro de 2011, é premiado. Teorías de lo fantástico, de 2001, é hoje um livro esgotado no mercado, é um livro considerado paradigmático para os estudos do fantástico (não só no universo da língua espanhola, mas, hoje, no universo da língua portuguesa também). É uma obra de referência. Trás los límites de lo real, de 2011, Teorías de lo fantástico, de 2001, e nesse intervalo, várias obras críticas dedicadas ao horror, ao medo, ao Edgar Allan Poe... desse seu conjunto da obra teórica ou crítica, qual título você destacaria e também por quê? 
R.: Bueno, yo que creo que los dos que has citado además de esos trabajos que tienen que ver más con la historiografía, con la literatura comparada o con los estudios de recepción (como los que dediqué a Hoffmann y Poe), tema este que me interesa mucho; ahora estoy embarcado en un estudio sobre la recepción e influencia de Lovecraft en la cultura española. Pero los trabajos que más eco han dado a mis ideas y de los que, en el fondo, estoy más contento son Teorías de lo fantástico (2001) y Trás los límites de lo real. Una definición de lo fantástico (2011). El primero lo armé mientras escribía mi tesis doctoral y es un libro que abrió muchos caminos pues en español nunca se había publicado una obra que recopilara varias de las principales voces sobre teoría de lo fantástico, desde Todorov a Rosemary Jackson, pasando por Bozzetto, Susana Reisz o Rosalba Campra. Creo que el gran acierto del libro fue reunir muchas y diversas formas de entender lo fantástico. Un libro que todavía sigue muy vivo en las librerías... Tras los límites de lo real supone la culminación de 10 años de trabajo teórico, pues en él logré exponer mi propia idea de lo fantástico, siempre desde una perspectiva general, no sólo literaria, pues lo que planteo sirve también para el cine, el teatro o el cómic, para cualquier otra forma artística que juegue con lo fantástico. Creo que es mi libro fundamental, si tuviera que escoger uno, pues en él está mi propia voz (en teorías de lo fantástico, la mía se unía a la de los grandes maestros). Y lo subtitulo Una definición de lo fantástico porque es eso, una definición más, la mía, en debate y relación con los que me han precedido, sin voluntad alguna de clausurar la reflexión teórica sobre lo fantástico. 
P.: Sua presença física no Brasil, a pessoa David Roas está mais ou menos ligada ao ano de 2011, a sua participação no segundo Colóquio Internacional Vertentes do Fantástico na Literatura, realizado pela Unesp, no campus de São José do Rio Preto, um projeto especificamente de um grupo de pesquisa, do qual o David hoje faz parte, "Vertentes do Fantástico na Literatura". Depois David retorna em 2012, no 1으 Congresso Vertente do Insólito Ficcional, realizado na UERJ, Rio de Janeiro, ambos na região sudeste, também promovido por um grupo de pesquisa do qual David também faz parte hoje, "Nós do insólito, vertente da ficção, da teoria e da crítica". A partir daí, eu tenho acompanhado e sei que o David tem sido convidado para vários eventos. Não tem podido ir, por razões de uma agenda, que é natural. Tem sido referenciado em todo e qualquer evento que se faz em torno do fantástico, do mais extremo sul do Brasil ao mais extremo norte e isso tem permitido diálogos com a Brumal, de que David vai falar já, participações unificadas e recentemente um livro seu lançado no Brasil pela editora da Unesp. Como é que o David, crítico do fantástico, teórico do fantástico, ficcionista do fantástico, diretor de um grande grupo de pesquisa, o Grupo de Estudios sobre lo Fantástico, aqui na Universidade Autônoma de Barcelona... Como é que o David pensa tanto os estudos, as pesquisas do fantástico no Brasil, tendo esses movimentos como representação, e as relações hoje entre os pesquisadores brasileiros, o estudo no Brasil e o que se faz no mundo como um todo e em particular aqui em Barcelona, em torno do GEF? 
R.: Reconozco que cuando fui aquel primer año a São José do Rio Preto conocía muy pocos estudios brasileños sobre lo fantástico, no tenía idea de lo que la gran potencia investigadora de Brasil en relación a dicho asunto, pues pude entrar en contacto con varios grupos de investigación, que desde 2011 siguen aumentando en número. La verdad es que en esa primera visita me sentí muy feliz, puesto que en España sólo existía mi equipo (GEF, Grupo de Estudios sobre lo Fantástico), al que ahora se ha unido otro de la Universidad de León. Es cierto que había investigadores particulares, doctorandos de diversas universidades dedicando sus tesis a lo fantástico, pero el gran desarrollo se ha producido coincidiendo - azar o no - con la publicación en 2001 de mis Teorías de lo fantástico. No quiero decir que yo abriera camino, pues ya había trabajos - muy pocos - desde los 80 , pero sí que es cierto que es en los últimos 15 años que la investigación sobre lo fantástico ha crecido de forma exponencial en España. EN esa primera estancia en Brasil también me di cuenta de la mucha gente que ahí estaba trabajando sobre lo fantástico, la gran formación en teoría literaria que tienen los investigadores (en España todavía domina la vieja filología, que vive aislada de la teoría literaria, como si fueran dos mundos separados). En Brasil, hablando con los investigadores, escuchando las ponencias, los congresos los dos que he ido y los dos en que he participado desde fuera-, he podido comprobar la enorme calidad de los investigadores. Yo creo que en el ámbito del estudio sobre lo fantástico el país "no inglés" con mayor y mejor producción por la cantidad de investigadores y de proyectos y de revistas y de publicaciones 
que se están haciendo. También me fascinó otra aspecto: Brasil y España han "sufrido" la misma historia en lo que se refiere a los estudios literarios sobre lo fantástico. Como en España, en Brasil siempre ha habido literatura fantástica, pero no se le hizo caso, nadie quiso investigar sobre ella, privilegiando lo realista, lo costumbrista. Es fascinante ver cómo se parecen nuestros países en eso, algo que también ocurre en otros países latinoamericanos (Perú, México, Chile...). En esas estancias en Brasil viví momentos muy felices, y sigo feliz por seguir colaborando con proyectos que se radican en Brasil porque yo creo que le están dando una enorme presencia a lo fantástico en los estudios literarios y, sobre todo, reivindicando (reescribiendo) su historia en nuestras lenguas.

P.: A Brumal nasceu revista específica da área, ligada ao GEF, dirigida por David. Um grupo internacional, representado no mundo inteiro, faz parte da Brumal, onde há um conjunto de pesquisadores brasileiros, colaborando nos seus conselhos, comitês, nas avaliações... E tem-se percebido que nos números da Brumal que têm sido publicados, sempre há uma contribuição de brasileiros, seja em artigo, seja em resenha... Como é que o David avalia essas relações entre a Brumal e a comunidade científica brasileira que estuda o fantástico e que tem tentado participar e contribuir com a publicação?

R.: Eso conecta con lo que yo decía antes. A la revista Brumal cada vez llegan más artículos de investigadores/as de Brasil, con una calidad media muy buena. Son trabajos tanto sobre autores canónicos de la literatura en portugués, como de carácter comparatista, transmedial e intermedia. Eso también 
me hace muy feliz, y espero que sigamos intercambiando ideas en próximos números de la revista y en los eventos que vayamos organizando en España y en Brasil en los próximos años. También quiero recordar que la presencia lusófona en Brumal es destacada, pues Flavio García es miembro del Consejo de Redacción, y en el Comité Científico contamos con las brasileñas Marisa Gama-Khalil y Karin Volobuef, y con los los portugueses Carlos Reis y Maria João Pires. Poco a poco estamos creando una gran red de investigadores, más allá de diferencias lingüísticas y geográficas. Nos une lo fantástico, y eso es lo esencial.

P.: Em 2012, David esteve no 1 을 Congresso Internacional da UERJ, cujo tema foi Vertentes Teóricas e Ficcionais do Insólito. Em 2014, fisicamente, por razões funestas, não pôde estar no 2 은 Congresso, mas participou indiretamente porque mandou o texto que foi alvo de discussão e está publicado no volume (Re) Visões do fantástico: do centro às margens; caminhos cruzados. Na UERJ, nós temos um grupo de pesquisa, e a partir desse grupo de pesquisa foram celebrados convênios com a Universidade de Coimbra, Centro de Literatura Portuguesa, dirigido pelo Carlos Reis, a que David acabou de se referir quando tratou da Brumal, e temos, mais recentemente, um convênio com a Universidade Autônoma de Barcelona, intermediado pelo GEF. O primeiro produto desse convênio com Coimbra é, este ano, o 3 o Congresso Internacional, no qual a personagem vai ser o centro. Temos um projeto novo, articulando a relação com o convênio que temos com Barcelona, projeto que, na verdade, não partiu, a princípio, nem do grupo da UERJ nem do 
grupo da UAB, mas outro colaborador nosso, Felipe Furtado, professor português da Universidade Nova de Lisboa, autor de $A$ construção do fantástico na narrativa, que sugeriu que criássemos um dicionário digital do insólito ficcional. Nesse universo, surgiu a ideia de estabelecer uma parceria efetiva com o David, com o GEF, e de ter uma cooperação integrada. Como é que o David pensa esse momento de uma correlação Europa/América, Barcelona/Rio de Janeiro, universo de língua portuguesa/universo de língua espanhola, pesquisa do fantástico, essa ideia de um dicionário digital hipertextual do insólito ficcional com colaboradores internacionais que obviamente o GEF, sediado na Europa, vai ser, talvez, um dos grandes pontos de radiação no continente europeu?

R.: Lo primero que debo decir es que tengo mucha envidia... ¿por qué no se me ocurrió a mí este proyecto? La verdad es que creo que es un proyecto excepcional, que demuestra algo que ya he dicho antes: la potencia que tienen los estudios fantásticos en la actualidad y cómo se debe trabajar en ellos. Debemos olvidarnos - sin perderlos de vista, valga la paradoja - de conceptos cerrados como nación y lengua. Porque la perspectiva debe ser internacional e intermedial, combinar los estudios sobre literatura con los estudios sobre artes, y todo en varias lenguas. Es un proyecto que irá creciendo, ampliándose con investigadores de más países (ahora involucra a Portugal, Brasil y España), porque es necesario vincular a más investigadores de otras lenguas, crear una enorme red. Un buen ejemplo de esto es el convenio que hemos firmado entre la UAB y la UERJ. Hay que seguir estableciendo contactos, creando convenios. 
También va a ser una forma de dar visibilidad a lo fantásticos en países donde ha recibido poca o nula atención. A diferencia de lo que ocurre en el mundo anglosajón o en Francia, en España y en los países latinoamericanos todavía queda mucho por hacer.

P.: Felipe Furtado ofereceu-nos, graciosamente, a edição de um livro que já tem título: O fantástico mecanismo de construção narrativa na obra de H. P. Lovecraft. Esse livro gerou a ideia de que, no próximo ano, em 2017, quando se completam 80 anos de falecimento de Lovecraft, fizéssemos no Brasil, no universo do nosso encontro que é nacional, um encontro nacional com uma abertura internacional, cujo título-tema deve ser, a princípio, "80 anos sem Lovecraft; mais de um século com sua obra". Júlio França, nosso colega de UERJ, diante da proposta, disse: "por que não convidar David Roas para este evento? David Roas é um apaixonado pelo Lovecraft". David é um apaixonado por Lovecraft? David vai em 2017 ao Rio de Janeiro?

R.: Un encuentro como ese no puedo perdérmelo, por supuesto. Me apetece muchísimo. Además, en los próximos meses (abril a junio) voy a estar en Brown University investigando sobre Lovecraft, pues en la John Hay Library tienen toda la bibliografía de él y sobre él. Estar 3 meses en Providence, la ciudad en la que nación y murió Lovecraft va a ser muy excitante. Desde leí con 15 años "The Call of Cthulhu", caí fascinado para siempre por Lovecraft. Es cierto que era un individuo horrible, racista, filofascista, pero como escritor no exagero en calificarlo de genio. No he podido dejar de leerlo desde entonces... Respondiendo a tu pregunta: pues sí, me declaro fan total de H. P. Lovecraft, uno de los auténticos maestros de lo fantástico. 
Sin él, la literatura y el cine fantásticos no hubieran sido lo mismo: esa forma de entender lo fantástico vinculándolo a lo mítico y arquetípico, su mezcla con la ciencia ficción, han sido determinantes para la evolución de lo fantástico. Cuando empecé a leerlo yo ya era muy fan de Poe y por esas mismas fechas descubrí a Borges (Dios)... En muchos de mis trabajos he acudido a Lovecraft, sobre todo en mis estudios sobre el miedo y el lenguaje, pero nunca me había metido a fondo en su obra. Pero desde hace un par de años, he empezado con el estudio de su recepción e influencia en la cultura española, y espero pronto convertirlo en libro... Todo esto justifica que haya aceptado la invitación de Flavio para participar en el congreso de 2017 en Río de Janeiro dedicado a Lovecraft, y también ha sido lo que me ha decidido a organizar en mi universidad un congreso dedicado al horror en el que dedicaremos buna parte de las mesas a la obra de Lovecraft ( $y$ a la de otra gran maestra de lo fantástico: Cristina Fernández Cubas). Será una gran fiesta a uno y al otro lado del Atlántico.

P.: Este ano, David Roas não vai ao nosso evento, especificamente sobre a personagem nos mundos possíveis do insólito ficcional, mas David está enviando Teresa López-Pellisa como representante do GEF. Qual a sua expectativa em relação a esse evento?

R.: Lo primero que hay que destacar es que - no creo equivocarme - nunca se ha organizado un congreso dedicado a ese aspecto: la representación, la figuración del personaje en relación estricta con lo insólito y lo fantástico. Será un congreso que va a generar buenas y nuevas ideas para abrir caminos 
en el estudio de lo fantástico. Creo que es muy innovador adentrarse en se aspecto, pues el personaje ha sido, quizá, el elemento menos trabajado en la teoría literaria. Hay mucho trabajo por hacer. Carlos Reis es un autor de referencia en los estudios narratológicos sobre el personaje y está trabajando mucho y muy bien sobre éste. Pero, insisto, todavía queda mucho por hacer, sobre todo desde lo fantástico... Por mi experiencia anterior en Brasil, estoy seguro de que será un congreso inmenso en todos los sentidos, tanto por el número de participantes como por la calidad de las ponencias. Es una pena no poder asistir, pues por las fechas me es imposible, pero asistirá, en representación del Grupo de Estudios de lo Fantástico, Teresa López-Pelllisa, excelente investigadora, que, además, es la Jefa de Redacción de la revista Brumal y con la que trabajo codo a codo desde 2011. Es una de las voces que más y mejor están trabajando en español sobre ciencia ficción.

P.: David, ficcionista do fantástico. David, um professor de teoria literária e literatura comparada, pesquisador do fantástico. Se David fosse mandar um recado para ficcionistas que queiram se dedicar ao fantástico ou que vêm se dedicando ao fantástico - não só no Brasil, mas no mundo como um todo -, que mensagem o David ficcionista, sem esquecer que é crítico e teórico, mandaria para esses escritores?

R.: Pues, que sigamos trabajando en lo fantástico, pues es una categoría (yo prefiero considerarla así), o un modo, o un género, da igual, que necesita, todavía, de mucha investigación. Creo que estamos abriendo muchos caminos a otros lados del Atlántico para que lo fantástico sea considerado una categoría 
digna de estudio. Además, lo fantástico sigue muy vivo, porque nunca desaparecerá: seguimos y seguiremos teniendo miedo de lo que no conocemos, de lo que no comprendemos, de lo que escapa a nuestra idea de realidad. Lo fantástico es una vía fundamental de reflexión sobre la realidad y sobre nosotros mismos. Nos muestra, en el fondo, lo absurdos y minúsculos que somos, que la realidad es un caos... Es una vía para experimentar lo que sabemos (o creemos saber) sobre la realidad, de pensar en todo lo que se nos escapa de ella. Por eso, está vinculado al horror, que surge de nuestra incomprensión. Lo fantástico no se agota, nunca dejaremos de pensar sobre esta categoría porque, como decía, nuestros miedos no desaparecen.

P.: Não particularmente para o escritor, mas especialmente para o crítico, para o teórico - David é crítico, teórico, professor -, que mensagem daria?

R.: No lo sé... Yo creo que la maravilla de trabajar en lo fantástico es darse cuenta de lo antes decía, de que no se agota, de que es una categoría, un género que merece toda nuestra atención y yo creo que, sobre todo, tenemos que hacer mucho trabajo para reivindicar lo fantástico en nuestras literaturas, en nuestras culturas. La literatura española ha sido aplastada por una crítica empeñada en entender la literatura - y el arte en general - como una producción exclusivamente realista. Lo mismo ha ocurrido en Perú, Brasil, México, Chile, Costa Rica... En Argentina no porque tienen a Borges y Cortázar... Por eso debemos reivindicar un cambio de mentalidad y perspectiva en los estudios literarios en nuestros países. Porque - no exagero - nos han engañado con nuestra historia, con nuestra tradición: 
han tratado de convencernos de que somos realistas. $Y$ eso es mentira. Si uno examina nuestras literaturas comprobará que es muy importante la presencia de lo fantástico, del realismo mágico, de lo real maravilloso, de la ciencia ficción. $Y$ todo eso debe salir a la luz. Esa es nuestra misión en los próximos años, a través de congresos, proyectos, publicaciones... Conseguir una transformación radical de la historia. Si se me permite: reescribirla y poner en su lugar todos esos géneros minusvalorados, pero que fueron y son muy cultivados $y$ leídos. Tenemos que participar en esa transformación de los estudios literarios y en la transformación de la historia literaria y artística en general para mostrar lo que no han querido que esté - hasta ahora - en la historiografía cultural de nuestros países. Yo creo que eso es la idea fundamental: batallar por convertir la historia en algo más cercano a la realidad y desterrar esa construcción falsa de una literatura realista apegado a la cotidianidad. Basta examinar la obra de los grandes autores y autores de nuestros países (en literatura o cine) y comprobar la importante presencia de obras fantásticas.

P.: Tudo que o David disse até agora foi, de certa maneira, conduzido por perguntas. Para encerrarmos, o que o David gostaria de dizer que não tenhamos perguntado, motivado, provocado?

R.: Hoy hemos hablado de cosas muy, muy interesantes acerca del estudio de loa ficción fantástica. Por eso quiero volver a reivindicar lo que antes planteé: pese a la distancia entre nuestros países, entre los dos continentes, debemos unir esfuerzos y energía para colaborar y difundir lo que hacemos a uno y otro lado del Atlántico. Olvidarnos de las distancias 
- en todos los sentidos - y colaborar, ampliar los canales de comunicación. Los contacto que mantenemos entre el grupo de Flavio García en la UERJ, los grupos de la UNESP, el GEF y otros grupos que empiezan a crearse en Perú, Chile o México nos permitirán crear una amplia red de estudios sobre lo fantástico. Y el diccionario hipertextual va a ser una obra muy importante y un medio excelente para desarrollar esas colaboraciones... Yo creo que más que preguntar, lo que quiero es volver a insistir en ello: en la necesidad de trabajar en común, de unir esfuerzos, perspectivas, metodologías, conocimientos... Y el mundo digital es perfecto para ello. 